\title{
Methodology for the Study of the Air Dispersion of the Industrial Contaminants Taking into Account the Orography ${ }^{\dagger}$
}

\author{
María José Suárez López 1,*, Laura García Expósito ${ }^{1}$, Eduardo Blanco Marigorta ${ }^{1}$,

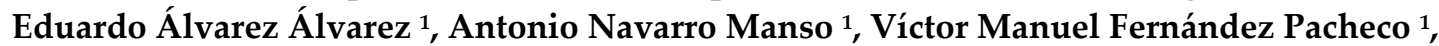 \\ Elena Antuña Yudego ${ }^{2}$ and Juan Luis Carús Candás ${ }^{2}$
}

1 Energy Department, University of Oviedo, EDZE 33203 Gijón, Spain; garciaexpositolaura@gmail.com (L.G.E.); eblanco@uniovi.es (E.B.M.); edualvarez@uniovi.es (E.A.A.); navarroantonio@uniovi.es (A.N.M.); victorpacheco.ing@gmail.com (V.M.F.P.)

2 TSK Company, Ada Byron, 220 Gijón, Asturias, Spain; elena.antuna@grupotsk.com (E.A.Y.); juanluis.carus@grupotsk.com (J.L.C.C.)

* Correspondence: suarezlmaria@uniovi.es; Tel.: +34-985-182-114

+ Presented at the 2nd International Research Conference on Sustainable Energy, Engineering, Materials and Environment (IRCSEEME), Mieres, Spain, 25-27 September 2018.

Published: 2 November 2018

\begin{abstract}
Air pollution is one of the consequences of the industrial development, which causes a lot of health and environmental problems. For these reasons, the quality of the air is one of the major concerns of regional, national and European governments. All of them are developing strict normative to reduce the emissions of contaminants. The quality of the air can be analysed by means of numerical simulations. In this paper, a methodology based on Computational Fluid Dynamics (CFD) is described. This technique allows evaluating the dispersion of industrial-type air pollutants in a relatively large area, taking into account the orography, buildings and so on. Also, specific models are studied in order to consider the specific characteristics of the industrial contaminants and particles.
\end{abstract}

Keywords: modelling; particles; air quality; air pollutants; CFD

\section{Introduction}

One of the consequences of the industrial development is air pollution, which is rising due to the increase in city populations, the high consumption of fossil fuels and the widespread use of private cars. Air pollution causes a lot of health and environmental problems. Specifically, it has been calculated that there are around 500,000 premature deaths per year in Europe due to air contamination [1]. Also, the highest concentrations of gaseous pollutants are usually located in urban agglomerations.

For these reasons, the quality of the air is one of the major concerns of regional, national and European governments. Authorities are developing strict regulations and controls in order to reduce the emissions of pollutant gases and particles. According to the European Union, these measures should ensure a clean atmosphere, free of anthropogenic contaminants by 2030 [2].

To analyse the quality of the air, the modelling of the atmospheric contamination behaviour is one of the most important tools. Several software tools have been developed during last years in order to evaluate the air pollution, such as AERMOD [3], CALPUFF [4], OSPM [5]. These tools enable the study of current conditions and, also, the prediction of new situations with a reasonable cost (economic and computational time) in both urban areas and industrial environments with different 
spatial spans and detail level depending on each software. Usually, they have a closed architecture and most of them are focused on the analysis of the dispersion of specific contaminants such as $\mathrm{SO}_{2}$, $\mathrm{NO}_{2}, \mathrm{PM}_{10}, \mathrm{PM}_{2.5}, \mathrm{~Pb}, \mathrm{VOC}, \mathrm{NH}_{3}[1,6]$. These codes use only basic equations of fluid movement, but they include photochemical models and different databases such as air quality, transport, weather and so on.

However, there are other tools, which enable the implementation of these analyses more precisely and without any restrictions. One of the most popular tools is Computational Fluid Dynamics (CFD) designed for the study of fluids in general. Specifically, it is possible to evaluate the dispersion of any substance in different environments, and it is especially useful at small or mediumscales taking into account the orography, buildings, etc. [7].

This paper describes a methodology based on CFD to study the dispersion of industrial-type air pollutants in a relatively large area. This methodology enables the simulation of 3D geometries taking into account the terrain orography and the study of the effect of the wind around the buildings and other constructions. Also, this tool allows considering the specific characteristics of the industrial contaminants (density, concentration, toxicity, etc.) and the particles if they exist with the pollutants by using specific models.

\section{Materials and Methods}

The numerical simulations of the dispersion of air pollutants are performed using the CFD code ANSYS, solving the unsteady-state Reynolds averaged Navier-Stokes equations through the finite volume method. With this methodology, 3D geometries can be generated and simulated considering the orography of the terrain with domain dimensions relatively large, or even, the effect of the wind around the buildings, as it can be seen in Figure 1. Normally, the domains are discretized with unstructured meshes formed by triangular prism cells. These meshes are refined at the regions where there are potentially higher field gradients, such as the atmospheric boundary layer or nearby buildings. The number of cells can vary between 500,000 and 10,000,000 in function of the simulation type.

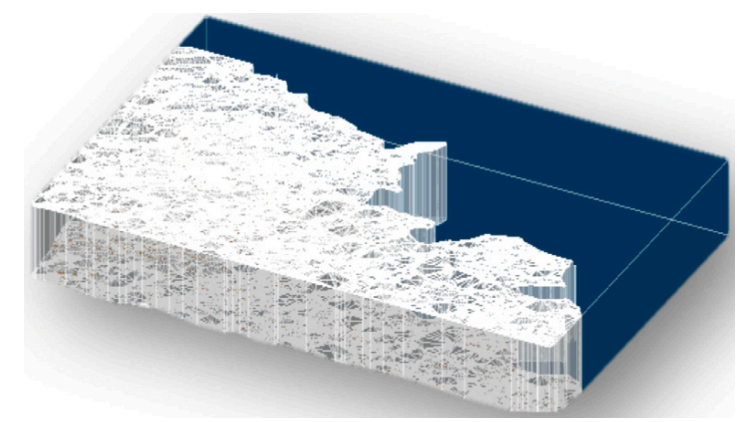

(a)

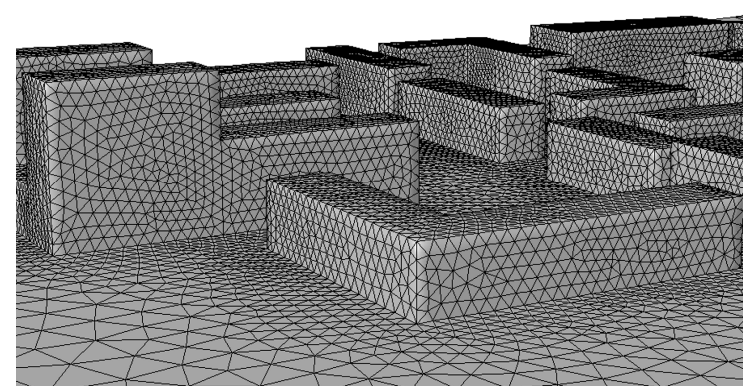

(b)

Figure 1. (a) Geometry representing an area of Gijón (dimensions of the domain: $14.5 \mathrm{~km} \times 10 \mathrm{~km} \times 1$ $\mathrm{km})$; (b) Details of the mesh taking into account the buildings.

Once the geometry and mesh have been generated, multi-species models are used to study the mixing and transport of chemical species by solving conservation equations describing convection, diffusion and reaction sources for each component. In this case, there is only a species mixing without chemical reactions. Then, ANSYS predicts the local mass fraction of each species $Y_{i}$, through the solution of a convection-diffusion equation for the $i$ th species. The general form of this conservation equation is:

$$
\frac{\partial}{\partial t}\left(\rho Y_{i}\right)+\nabla \cdot\left(\rho \vec{v} Y_{i}\right)=-\nabla \cdot \vec{J}_{i}+R_{i}+S_{i}
$$


where, $R_{i}$ is the net rate of production of species $i$ by chemical reaction and $S_{i}$ is the rate of creation by addition from the dispersed phase plus any user-defined sources and the diffusion flux of species $i$ is $\vec{J}_{i}=-\left(\rho D_{i, m}+\frac{\mu_{t}}{S c_{t}}\right) \nabla Y_{i}$ for turbulent flows.

Moreover, when these contaminants have particles, the Lagrangian discrete phase model is selected to study their behaviour together with these gases pollutants. This model follows the EulerLagrange approach. The fluid phase is treated as a continuum by solving the time-averaged NavierStokes equations, while the dispersed phase is solved by tracking a large number of particles through the calculated flow field. The dispersed phase can exchange momentum, mass and energy with the fluid phase. A fundamental assumption made in this model is that the dispersed second phase occupies a low volume fraction, even though high mass loading $\left(\left(\dot{m}_{\text {particles }}\right) \geq\left(\dot{m}_{\text {fluid }}\right)\right)$ is acceptable. The particle trajectories are computed individually at specified intervals during the fluid phase calculation by integrating the force balance on the particle. This force balance equates the particle inertia with the forces acting on the particle, and can be written (for the $\mathrm{x}$ direction in Cartesian coordinates) as:

$$
\frac{d u_{p}}{d t}=F_{D}\left(u-u_{p}\right)+\frac{g_{x}\left(\rho_{p}-\rho\right)}{\rho_{p}}+F_{x}
$$

Also, the gravity and the density variations due to thermal changes are taken into account assuming an ideal gas behaviour. Furthermore, turbulent effects in the fluid flow are considered by means of the K-epsilon-RNG model [8], including buoyancy effects and appropriate boundary conditions are defined. Normally, to represent the domain a velocity inlet condition in the input is used, while the output is represented by a constant static pressure value. Both buildings and bottom surface are considered wall conditions, while the upper and lateral surfaces are considered frictionless walls.

Regarding the solution procedure, a second order discretization scheme is selected for the governing equations at each cell in order to assure good calculation accuracy. Besides, the convergence criterion to conclude the iterative computational process is established in values lower than $10^{-5}$ for the normalised residuals of each governing equation.

\section{Results}

This methodology allows obtaining all details of the dispersion of contaminants (gases and particles) in both cases, large areas and smaller zones with buildings. Furthermore, concerning the results, it offers a lot of possibilities: contours of velocity, temperature, pressure, concentration, etc.; also, isoconcentration 3D maps, velocity vectors, and so on. All these results can be obtained varying with the height, at a specific elevation or in a determined zone. As an example, Figure 2 shows the concentration of the pollutants in the symmetry zone for two cases, when the contaminant gas is lighter (left) or heavier than the air (right). In the first case, the pollutant gas has a lower density than the air and, as it can be seen, it goes up and dissipates. In the second case, the contaminant gas, at the beginning, it goes up to about $200 \mathrm{~m}$ and then, goes back to fall down diffusing and scattering over the surface. 

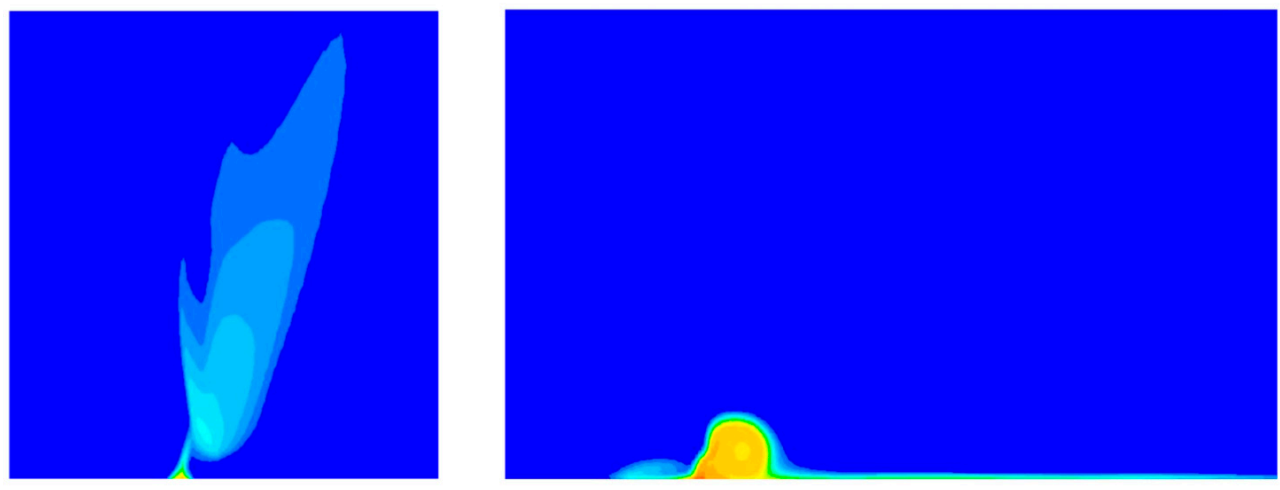

Figure 2. Mass fraction of the pollutants when the contaminant gas is lighter than the air (left figure); pollutants when the contaminant gas is heavier than the air (right figure).

\section{Conclusions}

The industrial development causes an increase of air pollution, among other things. The pollution provokes a lot of health and environmental problems and therefore, all governments are developing strict regulations and controls to reduce the gases emissions.

The quality of the air can be analyzed by modelling the atmospheric contamination behavior. There are several tools to evaluate the air pollution. In this paper, a methodology based on Computational Fluid Dynamics (CFD) has been described, taking into account the dimensions of the domains, the type of mesh and specific models in order to consider the specific characteristics of the industrial contaminants and particles. Also, among the results obtained, one example has been shown analyzing the dispersion of the gas pollutant when it is lighter and heavier than the air.

Author Contributions: M.J.S., L.G. and E.B. conceived and designed the models; M.J.S. and L.G. executed the numerical simulation; M.J.S., E.B. and E.Á. analyzed the data; A.N. and J.L.C. contributed materials; V.M.F. and E.A. performed the analysis of possible tools; M.J.S. and E.B. wrote the paper.

Conflicts of Interest: The authors declare no conflict of interest.

\section{References}

1. European Environment Agency. Air Quality in Europe - 2017 Report; No 13; European Environment Agency: Copenhagen, Denmark, 2017; p. 56.

2. Council of the European Union. Comunicación de la Comisión al Parlamento Europeo, al Consejo, al Comité Económico y Social Europeo y al Comité de las Regiones-Programa «Aire Puro» para Europa; Council of the European Union: Brussels, Belgium, 2003; p. 12

3. Cimorelli, A.; Perry, S.; Venkatram, A.; Weil, J.; Pain, R.; Wilson, R.; Lee, R.; Petrs, W. AERMOD - description of Model Formulation. v. 98314 (AERMOD and AERMET) and v. 98022 (AERMAP); Technical Report; United States Environmental Protection Agency (US-EPA), RTP, NC 27711; 1998.

4. Scire, J.S.; Strimaitis, D.G.; Yamartino, R.J. A User'S Guide for the CALPUFF Dispersion Model; Earth Tech.: Concord, MA, USA, 2000.

5. Berkowicz R. OSPM a parameterised street pollution model. J. Environ. Monit. Assess. 2000, 65, 323-331.

6. Di Sabatino, S.; Buccolieri, R.; Pulvirenti, B.; Britter, R. Simulations of pollutant dispersion within idealised urban-type geometries with CFD and integral models. Atmos. Environ. 2007, 41, 8316-8329. 
7. Santiago, J.L.; Borge, R.; Martin, F.; de la Paz, D.; Martilli, A.; Lumbreras, J.; Sanchez, B. Evaluation of a CFD-based approach to estimate pollutant distribution within a real urban canopy by means of passive samplers. Sci. Total Environ. 2007, 576, 46-58.

8. Launder, B.E.; Spalding, D.B. The numerical computation of turbulent flows. Comput. Methods Appl. Mech. Eng. 1974, 3, 269-289.

(C) 2018 by the authors. Licensee MDPI, Basel, Switzerland. This article is an open access article distributed under the terms and conditions of the Creative Commons Attribution (CC BY) license (http://creativecommons.org/licenses/by/4.0/). 